\title{
Temporal Variations in Methane Emissions from an Unconventional Well Site
}

\author{
Derek Johnson \\ West Virginia University \\ Robert Heltzel \\ West Virginia University \\ Dakota Oliver \\ West Virginia University
}

Follow this and additional works at: https://researchrepository.wvu.edu/faculty_publications

Part of the Engineering Commons

\section{Digital Commons Citation}

Johnson, Derek; Heltzel, Robert; and Oliver, Dakota, "Temporal Variations in Methane Emissions from an Unconventional Well Site" (2019). Faculty \& Staff Scholarship. 1260.

https://researchrepository.wvu.edu/faculty_publications/1260

This Article is brought to you for free and open access by The Research Repository @ WVU. It has been accepted for inclusion in Faculty \& Staff Scholarship by an authorized administrator of The Research Repository @ WVU. For more information, please contact beau.smith@mail.wvu.edu. 


\title{
Temporal Variations in Methane Emissions from an Unconventional Well Site
}

\author{
Derek Johnson, ${ }^{*}+\odot$ Robert Heltzel, ${ }^{\dagger}$ and Dakota Oliver $^{\dagger}$ \\ ${ }^{\dagger}$ Center for Alternative Fuels, Engines, and Emissions, Mechanical and Aerospace Engineering Department, West Virginia \\ University, P.O. Box 6106, Morgantown, West Virginia 26506, United States
}

\section{Supporting Information}

\begin{abstract}
Studies have aimed to quantify methane emissions associated with the growing natural gas infrastructure. Quantification is completed using direct or indirect methods - both of which typically represent only a snapshot in time. Most studies focused on collecting emissions data from multiple sites to increase sample size, thus combining the effects of geospatial and temporal variability (spatio-temporal variability). However, we examined the temporal variability in methane emissions from a single unconventional well site over the course of nearly 2 years ( 21 months) by conducting six direct quantification audits. We used a full flow sampling system that quantified methane mass emissions with an uncertainty of $\pm 10 \%$. Results showed significant temporal variation in methane mass emissions ranging from 86.2 to $4102 \mathrm{~g} / \mathrm{h}$ with a mean of $1371 \mathrm{~g} / \mathrm{h}$. Our average emissions rate from this unconventional well pad tended to align with those presented in the literature. The largest

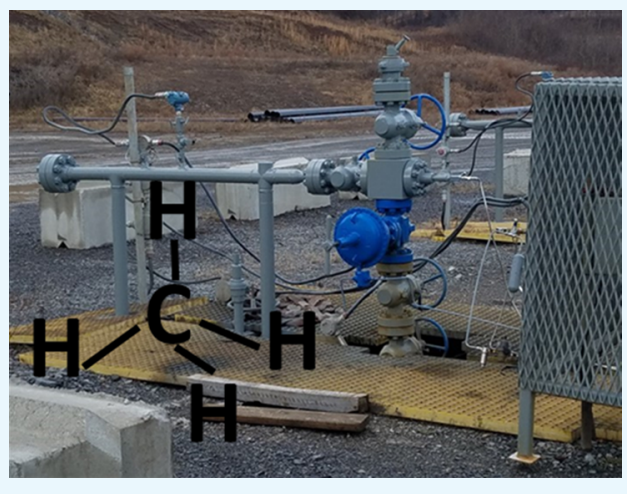
contributor to variability in site emissions was the produced water tank which had emissions rates ranging from 17.3 to $3731 \mathrm{~g} /$ h. We compared our methane mass emissions with the total production for each audit and showed that relative methane loss rates ranged from 0.002 to $0.088 \%$ with a mean of $0.030 \%$, typically lower than reported by the literature, noting that our data excluded well unloadings. We examined natural gas production, water production, and weather conditions for trends. The strongest correlation was between methane emissions and historical water production. Our data shows that even for a single site, a snapshot in time could significantly over-predict $(3 \times)$ or under-predict $(16 \times)$ methane emissions as compared to a long-term temporal average.
\end{abstract}

\section{INTRODUCTION}

Methane emissions from across the natural gas supply chain reduce the environmental and climate benefits of using natural gas instead of other hydrocarbon-based fuels. ${ }^{1,2}$ Methane, the main component in natural gas, is a potent greenhouse gas (GHG). The International Panel on Climate Change (IPCC) currently assigns methane a global warming potential (GWP) of 86 and 34 over 20 and 100 years, respectively. ${ }^{3}$ However, the US Environmental Protection Agency (EPA) currently uses an older IPCC GWP of $25 .{ }^{4}$ GWP compares the effects of various GHGs relative to carbon dioxide $\left(\mathrm{CO}_{2}\right)$ over a given time. Therefore, leaks of methane must be low for natural gas to offer a lower GHG footprint than other hydrocarbon-based fuels. Alvarez et al. estimated that total leak rates should be less than $3.2,1.0$, and $1.6 \%$ to see immediate net climate benefits for fuel switching from coal, diesel, and gasoline, respectively. ${ }^{1}$ In a recent article, we reviewed publications spanning the last decade which estimated anywhere from 1 to $17 \%$ of natural gas was lost along the supply chain. ${ }^{5}$

According to the EPA, natural gas emissions contributed to $31 \%$ of all methane emissions in 2015 . $^{6}$ Natural gas emissions were classified as either combustion, vented, or equipment leak emissions. ${ }^{7}$ Combustion emissions were all of the emissions in exhausts created from burning natural gas in either engines or burners. Vented emissions were those released by design of properly operating devices, i.e., emissions vented from pneumatic actuators which were powered by natural gas. Leaking emissions were those from equipment that were lost unintentionally due to component malfunction, i.e., leaking pipe threads. Recent studies have reported on the following sources of emissions including production sites, ${ }^{8,9}$ gathering and processing, ${ }^{10,11}$ transmission and storage, ${ }^{12-14}$ distribution, ${ }^{15}$ and the transportation sector. ${ }^{16}$

Unconventional wells that were hydraulically stimulated produced $67 \%$ of the US natural gas production in $2015 .^{17}$ Omara et al. observed that unconventional wells emitted 23 times more methane than conventional wells, which is of concern for the growing population of unconventional wells. ${ }^{18}$ However, when comparing emissions as a function of production, conventional wells emitted more productionnormalized emissions than unconventional wells. ${ }^{18}$ The purpose of this study was to examine the long-term temporal variation in methane emissions from an unconventional well site and compare these new data with those reported in the

Received: November 20, 2018

Accepted: February 6, 2019

Published: February 19, 2019 
literature and to assess any trends. The well site was located in the Marcellus region and included four unconventional wells and associated equipment. This site is unique in that it directly feeds the entire metropolitan area, and due to regional consumption constraints, production rates varied between audits based on local demand, see the Supporting Information Section S1 for site details. The data sets were examined with regards to reported trends in the literature and serve as an example that short duration snapshots in time may significantly under- or over-predict emissions from natural gas well sites. In fact, temporal variations have been identified as a contributor to differences between top-down and bottom-up approaches. ${ }^{19}$

\section{METHODS}

There are a variety of methods to measure methane emissions. One common method has been the direct quantification with systems such as the Hi-Flow Sampler. ${ }^{8,20}$ However, issues with its use in recent studies have been highlighted in articles. ${ }^{21,22}$ To eliminate any gas interference issues, we developed the full flow sampling (FFS) system, which has been detailed in the literature. $^{6}$ Variants of this system have been deployed in programs funded by the Environmental Defense Fund, Department of Energy, and Industry. The system has been used to measure methane emissions from unconventional natural gas sites, conventional gas sites, compression and storage facilities, heavy-duty vehicle fuel stations, and other sources. ${ }^{13,16,23}$ The system uses excessive dilution to ensure that methane concentrations in the sample are low. The system's methane analyzer is based on enhanced cavity spectroscopy, which eliminates the effects of gas composition. ${ }^{24}$ The system operates similarly to dilution tunnels used in automotive emissions measurements, whereby, the source of emissions is captured along with dilution air, and the dilute mixture is analyzed. The FFS is calibrated prior to use, and it has been demonstrated to have an uncertainty of less than $\pm 10 \%$ for methane emissions rates from 1 to 1000 grams per hour $(\mathrm{g} / \mathrm{h})$ using simulated methane leaks from mass flow controllers. Additional details on the system and methods are found in the Supporting Information Section S2.

All audits occurred during daylight hours. All equipment and sources of possible emissions were examined with a handheld methane detector (Eagle II, RKI Instruments). Only during the first audit was an optical gas imaging camera used to detect sources and verify full capture of the effluent stream (GF320, FLIR). The same sampling approaches and verifications with handheld units were used in subsequent audits. Sources that surpassed a threshold of 500 parts per million (ppm) were marked for quantification with the FFS and photographed. For quantification with the FFS, a site background methane concentration was collected during component set up. For steady leaks and losses, 30-90 s of data were recorded, averaged, and background-corrected. Any measurements that yielded methane emissions rates of less than $0.1 \mathrm{~g} / \mathrm{h}$ (such as multiple wellhead fluxes) were set to zero due to variability in background methane concentrations throughout audits. The only equipment not directly measured with the sampling hose were the enclosed gas processing units (EGPUs) and wellheads. The EGPU units contained a significant number of fittings and pneumatic controllers that operated on natural gas. As opposed to quantifying all point sources separately, the EGPUs were sampled as whole units using their system enclosure and sampling times varied, depending on operation status and emissions fluctuations. Their average emissions were background-corrected using the site background methane concentration. The wellheads were enclosed with a tent to measure the total flux from all components. Prior to sampling a well, the tent was erected above normal site soil, and background flux data were collected for background corrections of tented wellhead measurements. Tented measurement times were approximately 20-30 min, depending on methane enhancement above background and emissions variations.

This site also contained a produced water tank. Atop the tank were the vent, thief hatch, and fitting for monitoring equipment. Each was checked with the handheld unit and quantified separately when the thief hatch was closed. On multiple occasions (audits 2-6), the thief hatch was found opened and was sampled in this condition. The sampling hose was connected to a plastic sampling bin, which was used to sample effluent streams from larger sources while blocking any prevailing winds. The sampling bin remained elevated on at least one side to ensure that a seal was not created, which would have created a negative pressure and overestimated tank emissions.

The site contained two EGPUs, but only one exhaust stack included an adequate sampling port to examine exhaust stack emissions. To quantify these emissions, an S-style pitot tube was used with a handheld pressure sensor and a K-type thermocouple to estimate exhaust stack flow. Multiple bag samples were collected using a positive displacement pump and $10 \mathrm{~L}$ Tedlar bags. These bags were then transferred to the laboratory and analyzed with an MKS Fourier transform infrared analyzer. Additional information on component quantification is included in the Supporting Information.

\section{RESULTS AND DISCUSSION}

3.1. Results. Table S2 includes additional information for the audit conditions. Items that were identified as sources of methane emissions varied from audit to audit. The following items were a source of emissions during at least one audit: leaking components, natural gas-fueled thermoelectric generator, two EGPUs, four unconventional wellheads, a produced water tank, burner stacks, and a methanol injection system. Table 1 presents the summary data from all audits. Data regarding exhaust stack emissions can be found in the Supporting Information, but their contributions were found to be negligible, see Table S3.

A methanol injection system was installed sometime after the third audit and represented a substantial new source of emissions during audit 4 ( $\sim 31 \%$ of total). Its vent emissions were measured to capture multiple pneumatic actuations, which yielded an average emission rate of $540 \mathrm{~g} / \mathrm{h}$ (included in the other category). The largest single source of emissions was the produced water tank during audit 2 , which yielded an emissions rate of $3731 \mathrm{~g} / \mathrm{h}$ or about $91 \%$ of the total site emissions. It was initially thought that the emissions were higher than the first audit due to the opened thief hatch, however, it was also found in the opened position for all subsequent audits. In addition, the produced water tank also showed a significant variability in emissions, which contributed to the temporal variability in total site emissions. Its emissions rates ranged from 17.3 to $3731 \mathrm{~g} / \mathrm{h}$. Only one of the EGPUs was active during audit 2 , and it operated intermittently. Here, active refers to the unit's burner being active (producing exhaust stack emissions) not the status of the unit flowing produced gas. Active status as in producing or flowing gas is 


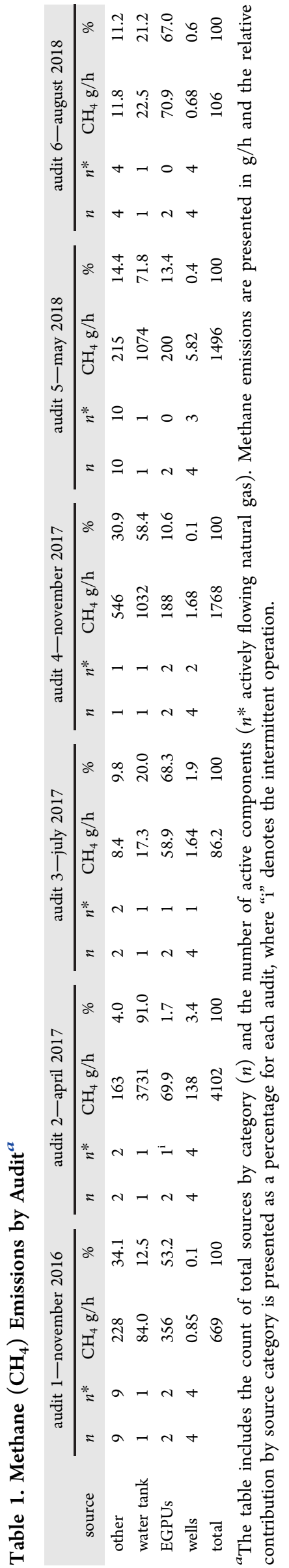

denoted in Table 1 for all components. Multiple dump events from the EPGU to the water tank occurred during its intermittent operation, which likely contributed to the higher tank emissions during audit 2. Its emissions were sampled between the intermittent dump events during audit 2 , and no audible dump events occurred during the other audits. Figure S12 presents an example of the variability in uncorrected methane concentrations collected from the thief hatch during this intermittent operation. Wellhead emissions are presented as the sum of all four wellheads. During audits 1 and 3-6, wellhead emissions were low, however, during audit 2 , a pneumatic valve on a wellhead operated intermittently, which contributed to higher emissions; see Figure S11 for an example of the variability in methane emissions due to a pneumatic valve operation.

Figure 1 presents the cumulative site emissions and includes a breakdown by the major categories of "wellheads", "water

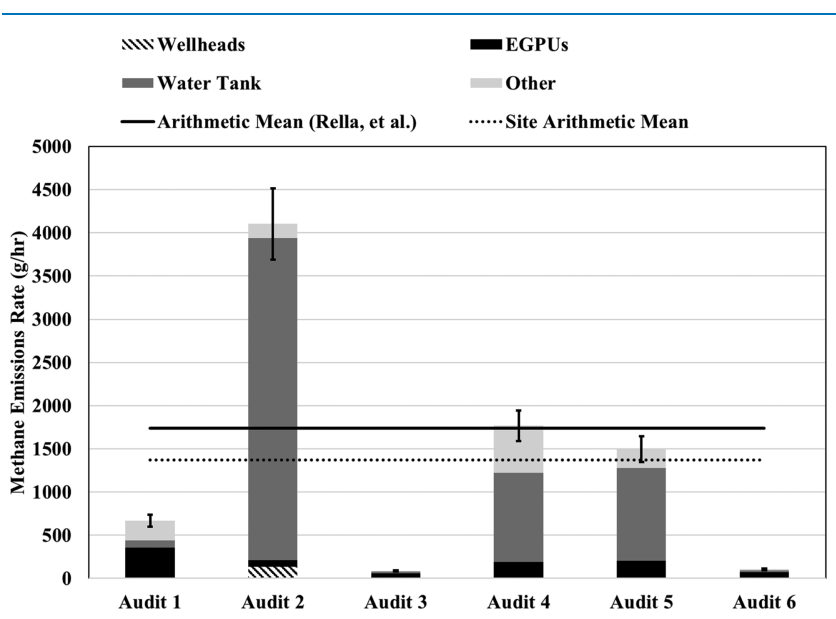

Figure 1. Combined audit results with the mean presented for comparison with data from Rella et al. $(n=117)$.

tank", "EGPUs", and "other", where other includes emissions from stacks (where applicable), quantified leaks above the threshold, and any controller vents or other sources that were also above the threshold. Error bars represent the $\pm 10 \%$ measurement uncertainty. Audits 1 and 2 do not include EGPU exhaust stack emissions even though they were active; however, if the emissions were within the range seen during audits 3 and 4, their impact would be less than 1\%. The EGPU burners were not active in audits 5 and 6 . The total for audit 3 includes exhaust stack emissions, which were measured from the only active EGPU. Audit 4's total includes twice the measured value, since both EGPUs were in active. Figure 1 also includes a line for the arithmetic mean of the emissions from our six audits and the arithmetic mean of well site emissions rates presented by Rella et al. ${ }^{25}$ It was noted that the well sites of the Rella et al. study were in the Barnett region, which may have different operating characteristics and older infrastructure. The figure shows that cumulative emissions varied significantly, ranging from $86.2 \pm 8.62$ to $4102 \pm 410 \mathrm{~g} /$ h. The mean emissions measured were $1371 \pm 137 \mathrm{~g} / \mathrm{h}(n=$ $6)$, which were lower than the arithmetic mean of Rella et al. ${ }^{25}$ $-1740 \mathrm{~g} / \mathrm{h}(n=117)$.

We examined wellhead emissions rates for each well over all audits. Table S4 includes the total natural gas and water production per well, which indicated if the well was active as well as its relative production for the site. On the basis of the 
analysis of the data, there were no clear trends between wellhead emissions and activity or production rate. The background-corrected emissions ranged from below the detection limit $(<\sim 0.1 \mathrm{~g} / \mathrm{h})$ to $134 \pm 13.4 \mathrm{~g} / \mathrm{h}$. The mean emissions rate was $6.19 \pm 0.6 \mathrm{~g} / \mathrm{h}$ with a median and standard deviation of 0.24 and $27.2 \mathrm{~g} / \mathrm{h}$, respectively $(n=24)$.

Table 2 presents the total measured site emissions, total natural gas (whole gas) production, and relative loss rates for

Table 2. Methane Emissions, Production, and Relative Losses

\begin{tabular}{|c|c|c|c|c|c|}
\hline & $\begin{array}{c}\mathrm{CH}_{4} \\
\text { emissions } \\
(\mathrm{g} / \mathrm{h})\end{array}$ & $\begin{array}{l}\text { whole gas } \\
\text { emissions } \\
(\mathrm{g} / \mathrm{h})\end{array}$ & $\begin{array}{l}\text { whole gas } \\
\text { production } \\
\quad(\mathrm{g} / \mathrm{h})\end{array}$ & $\begin{array}{c}\text { relative } \\
\text { loss } \mathrm{CH}_{4} \\
(\%)\end{array}$ & $\begin{array}{c}\text { relative loss } \\
\text { whole gas } \\
(\%)\end{array}$ \\
\hline audit 1 & 669 & 706 & $5.74 \times 10^{6}$ & 0.012 & 0.012 \\
\hline audit 2 & 4102 & 4329 & $4.64 \times 10^{6}$ & 0.088 & 0.093 \\
\hline audit 3 & 86 & 91 & $2.51 \times 10^{6}$ & 0.003 & 0.004 \\
\hline audit 4 & 1768 & 1866 & $7.79 \times 10^{6}$ & 0.023 & 0.024 \\
\hline audit 5 & 1496 & 1579 & $2.37 \times 10^{6}$ & 0.063 & 0.067 \\
\hline audit 6 & 106 & 112 & $4.50 \times 10^{6}$ & 0.002 & 0.002 \\
\hline mean & 1371 & 1447 & $4.59 \times 10^{6}$ & 0.030 & 0.032 \\
\hline yearly $^{a}$ & 21552 & 22744 & $6.88 \times 10^{7}$ & 0.031 & 0.033 \\
\hline Der ve & & & & & \\
\hline
\end{tabular}

both methane and whole gas. Gas analyses are presented in the Supporting Information and were $97.3 \%$ methane by volume or $94.8 \%$ by mass, thus, methane mass flow rates were divided by 0.948 to obtain whole gas emissions rates. Using the audit data with corresponding natural gas production for those days, the production-normalized methane emissions ranged from 0.002 to $0.088 \%$ of the production with a mean of $0.030 \%$. The mean whole gas loss rate was $0.032 \%$. The last row presents an alternative approach of using an average emissions rate of 1371 $\mathrm{g} / \mathrm{h}$ for the total duration of 655 days and the total natural gas production of 3602 MMSCF.

3.2. Comparisons with Site Emissions Measurements. Many operators participate in leak detection and repair programs. The current trend is to conduct annual audits with optical gas imaging technologies. However, these methods do not present data on total mass emissions rates. In addition, GHG reporting programs often use out-of-date emissions factors and include little information about site activity. Though our quantification method required direct component-level access at sites, they showed that mass emissions from a single site at the component level vary temporally. The goal of some studies was to examine larger populations of sites using direct or indirect quantification methods. Other study quantification methods included direct quantification with the Hi-Flow Sampler, downwind flux, and downwind tracer ratio methods. A recent study of co-measured sites has shown that downwind flux measurements using methods such as OTM33A may be less accurate than onsite estimates or tracer methods. ${ }^{26}$ We compare our data with campaigns from across the country to assess if our measurements aligned with emissions rates presented in the literature. We note that the natural gas composition, operating procedures, and equipment may vary from different regions, and these variables could contribute to different emissions profiles. Table S5 includes tabular data for comparison.

3.2.1. Direct. As mentioned above, the Allen et al. study, as have many others, used the Hi-Flow Sampler, and this work has been criticized. ${ }^{21,22}$ Howard suggests that sensor issues (transition and gas composition) could lead to underreporting of emissions data. ${ }^{22}$ However, a recent examination by Alvarez et al. suggested that sensor issues may be a part of discrepancies, but that operator practices and general lack of complete data sets could also lead to discrepancies. ${ }^{31}$ Therefore, we used data from Allen et al. to compare with our emissions. ${ }^{8}$

As a part of the Allen et al. study, they completed direct measurements at 20 natural gas production sites; however, five of those sites operated onsite compression and were excluded from our comparison. ${ }^{8}$ Allen et al. reported their emissions in standard cubic feet per minute, and we converted their values to $\mathrm{g} / \mathrm{h}$ with the following equation for comparison with our data. Only methane flow rates were used from Allen et al., neither their normalized data per well nor their whole gas data were examined for comparisons.

$$
\begin{aligned}
\mathrm{g} / \mathrm{h}= & \operatorname{SCFM} \times(60 \mathrm{~min} / \mathrm{h}) \times(28.3 \mathrm{~L} / \mathrm{CF}) \\
& \times(16 \mathrm{~g} / \mathrm{mol}) /(22.4 \mathrm{~L} / \mathrm{mol})
\end{aligned}
$$

Note that their total site data included estimates for tanks, whereas our data included direct tank measurements. Overall, our site maximum and mean values were comparable to measurements from both the Rocky Mountain (mean $+15 \%$, maximum -24\%) and Appalachian region (mean -32\%, maximum -29\%) measurements.

3.2.2. Indirect. Rella et al., ${ }^{25}$ Yacovitch et al., ${ }^{27}$ and Robertson et al., ${ }^{28}$ all used downwind flux measurements of the site emissions, whereas Omara et al., ${ }^{18}$ Goetz et al., ${ }^{29}$ and Yacovitch et al. ${ }^{30}$ used downwind tracer methods. Our lowest emissions were on the same order of magnitude as minimum detectable well pads measured by Rella et al. in the Barnett. Our maximum emissions were on the same order of magnitude as unconventional wells reported by Robertson et al. and the conventional wells reported by Omara et al. Our mean emissions were $20 \%$ lower than the mean of Rella et al., only $2 \%$ lower than the emissions reported by Robertson et al. for the Denver-Julesburg (DJ) basin, and only 16\% higher than Allen et al. for the Rocky Mountain region. Overall, our mean emissions were between the minimum and maximum values of other studies that included unconventional well sites. The results of Yacovitch et al. downwind flux measurements were significantly higher than our results and the results from other indirect measurement campaigns. ${ }^{27}$ Their experimental design in the Barnett shale region specifically focused on high emitting facilities, whereas other studies did not, therefore, their results were likely not representative of average site emissions. However, the mode for their production pads in the Fayetteville shale play was $1000 \mathrm{~g} / \mathrm{h},{ }^{30}$ which was similar to our mean emissions (e.g., $1371 \mathrm{~g} / \mathrm{h}$ ).

The results of interest were those of the unconventional well pads examined by Omara and Goetz, which were collected in the Marcellus. Our mean emissions were about 14 times lower than those of the unconventional well pads of Omara et al. and about 6.5 times lower than those reported by Goetz et al. The number of wells on unconventional well pads is usually more than one, and the equipment count typically increases with the number of wells per site. For the three sites measured by Goetz et al., the well counts were 9, 9, and 7 or about twice the number of wells on our site (4). For the sites measured by Omara et al., the well counts ranged from 1-9 with an average of 5 per pad. No composition data were reported by Goetz et al., but the compositions of wells measured by Omara et al. 


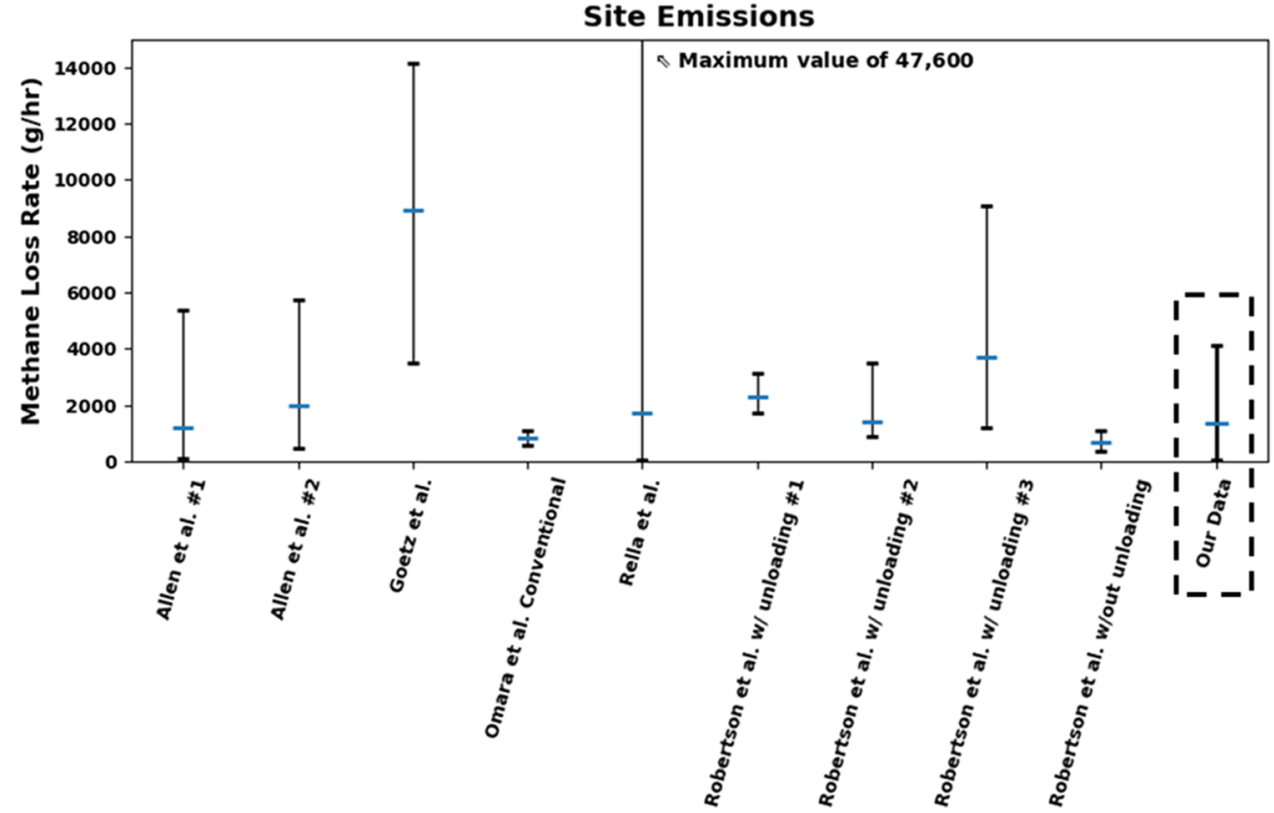

Figure 2. Comparison of our data with nine other sitewide measurement campaigns. The center represents the study mean with error bars representing the maximum and minimum reported values. (Allen et al. \#1-Rocky Mountain, Allen et al. \#2-Appalachian, Robertson \#1-Uintah, Robertson \#2-DJ, Robertson \#3-UGR).

Table 3. Comparison of Our Direct Component-Level Measurements with Direct Spatio-Temporal Measurements from the Literature $^{a}$

\begin{tabular}{|c|c|c|c|c|c|c|c|c|c|}
\hline \multirow[b]{2}{*}{$\begin{array}{l}\text { study } \\
\text { region } \\
\text { method }\end{array}$} & \multicolumn{3}{|c|}{ sites "leaks"-excludes tanks* } & \multicolumn{3}{|c|}{ pneumatic chemical injection pumps } & \multicolumn{3}{|c|}{ wellheads (non-zero) } \\
\hline & $\begin{array}{c}\text { ours } \\
\text { Marcellus } \\
\text { FFS }\end{array}$ & $\begin{array}{c}\text { Allen et al. } \\
\text { Rocky Mountain } \\
\text { Hi-Flow }\end{array}$ & $\begin{array}{l}\text { Allen et al. } \\
\text { Appalachian } \\
\text { Hi-Flow }\end{array}$ & $\begin{array}{c}\text { ours } \\
\text { Marcellus } \\
\text { FFS }\end{array}$ & $\begin{array}{c}\text { Allen et al. } \\
\text { Gulf Coast } \\
\text { Hi-Flow }\end{array}$ & $\begin{array}{c}\text { Allen et al. } \\
\text { Mid-Continent } \\
\text { Hi-Flow }\end{array}$ & $\begin{array}{c}\text { ours } \\
\text { Marcellus } \\
\text { FFS }\end{array}$ & $\begin{array}{l}\text { Kang et al. } \\
\text { Marcellus } \\
\text { flux chamber }\end{array}$ & $\begin{array}{c}\text { Townsend-Small et al. } \\
\text { various } \\
\text { flux chamber }\end{array}$ \\
\hline$n$ & 6 & 10 & 5 & 1 & 21 & 41 & 18 & 19 & 9 \\
\hline $\min$ & 6.04 & 24.3 & 170 & & & & $1.42 \times 10^{-1}$ & $6.30 \times 10^{-4}$ & $6.00 \times 10^{-4}$ \\
\hline $\max$ & 228 & 885 & 3578 & & & & 134 & 86 & 16.1 \\
\hline mean & 106 & 241 & 1223 & 540 & 614 & 60.6 & 8.26 & 11.25 & 5.61 \\
\hline
\end{tabular}

${ }^{a}$ Min, max, and mean are in units of $\mathrm{g} / \mathrm{h}$.

varied from 73 to $95 \%$ methane (average of $80 \%$ ), whereas our natural gas was $97 \%$ methane. Since higher hydrocarbons were produced at their sites, higher methane emissions could be attributed to any additional produced water and condensate tanks and associated equipment necessary for processing. We also note that Omara et al. daily production ranged from 456 to $78024 \mathrm{MCF} /$ day (average $14547 \mathrm{MCF} /$ day), whereas our average daily whole gas production ranged from 2978 to 9791 $\mathrm{MCF} /$ day (average $5766 \mathrm{MCF} /$ day). Goetz et al. also provided natural gas production for their sites in total annual production for 2012, and their average production was 7123 $\mathrm{MCF} /$ day, which was also higher than the average of our site. This suggests that their higher production rates may also be contributing to their higher methane mass emissions rates.

Figure 2 presents a comparative graphic of our data compared with those from the literature. Note that Figure 2 excludes some studies presented in Table S5. We examined the mean emissions from all 14 studies and used a modified $\mathrm{z}$-score to identify possible outliers $(>3.5),{ }^{32}$ these are marked in Table S5. The data presented includes the mean emissions in $\mathrm{g} / \mathrm{h}$ with the error bars representing the maximum and minimum reported values.

3.3. Component-Level Measurements. We also compared our measurements with component level measurements presented in the literature, including the results from Allen et al. To remove the impact of tanks, we used only their measured emissions data (excluding estimated tank emissions) and compared that data with our site emissions, excluding tanks. Table 3 shows that our nontank emissions were 2.3 times lower than those in the Rocky Mountain region and 11.6 times lower than those in the Appalachian region. The range of their estimated tank emissions rates was from 12.1 to $5191 \mathrm{~g} /$ h. Their estimated tank emissions matched well with our tank emissions, therefore, their site sources, excluding tanks, were likely higher than our direct measurements, as opposed to under estimated tank emissions. In addition, we compared our other emissions with their fugitive category. Our emissions are those presented earlier in the category of other with the exclusion of the methanol injection system of audit 4 . In addition, we excluded the emissions from the EGPUs since they had a separate category for pneumatic controls. In this comparison, we saw that our other emissions tended to be lower than their fugitive values in both regions. Allen et al. also characterized the emissions from 62 pneumatic chemical injection pumps. ${ }^{10}$ Though the methanol injection system was only at our site for one audit, its measured emissions were within $15 \%$ of the average emissions from the chemical injection pumps used in the Gulf Coast region. 
Regarding the wellheads themselves, there is limited data available on direct quantification of unconventional wellhead emissions alone. The most recent studies have examined abandoned or coal bed methane wells. Of our 24 wellhead measurements, we saw quantifiable emissions $(>0.1 \mathrm{~g} / \mathrm{h})$ on 18 occasions. Table 3 presents our non-zero wellhead emissions with those of non-zero measurements of wells measured by Kang et al. ${ }^{33}$ and Townsend-Small et al. ${ }^{34}$ Our non-zero mean was $8.26 \mathrm{~g} / \mathrm{h}$, and the mean of the combined data sets of Townsend-Small et al. and Kang et al. was $8.43 \mathrm{~g} / \mathrm{h}$. This may suggest that wellhead emissions or fluxes are similar regardless of well type, age, status, or location. However, our non-zero data set $(n=18)$ was skewed, therefore, we used the modified $\mathrm{z}$-score approach to identify possible statistical outliers which strongly influenced the non-zero mean. Removing these possible outliers (emissions rates of 1.33, 4.29, 4.65, and 134 $\mathrm{g} / \mathrm{h}$ ) reduced the non-zero average wellhead emissions to 0.33 $\mathrm{g} / \mathrm{h}$, at least 1 order of magnitude lower than their mean values. We found no correlation between site activity and zeros or possible outliers. Out of the total number of wellhead measurements $(n=24)$, zero emissions occurred $25 \%$ of the time $(n=6)$, whereas statistical outliers accounted for $17 \%$ of measurements $(n=4)$. Alternatively, the geometric mean of our non-zero emissions was $0.6 \mathrm{~g} / \mathrm{h}$. This may suggest that new unconventional wellheads may tend to have lower emissions than others. In this case, wellhead emissions were low and did not contribute significantly to sitewide emissions (maximum < $1.9 \%)$

3.4. Variability and Correlations. As discussed earlier, the produced water tank was the predominant source of methane emissions for audits 2, 4, and 5, and its mass emissions varied by a factor of 216. Most produced water tank vents are not controlled and, ultimately, vent to the atmosphere. Methane emissions from vents or hatches can occur via vented gas during dumping, displacement of gases within the tank due to liquid level changes, and desorption of gases from the liquids. Both natural gas and water production rates were available for this site daily. We examined the total site methane emissions, tank emissions, and nontank emissions based on the daily natural gas and water production. Figures S13 and S14 show that there were no significant correlations between total emissions compared with natural gas or water production. At the same time, we compared nontank emissions with natural gas production alone and found a weak positive correlation between increased nontank emissions and production, see Figure S15. Since tank emissions were the predominant and most variable source, we compared tank only emissions with the water production, which showed no significant correlation, see Figure S16. However, based on the three possible avenues of tank emissions described above, we then examined correlations of tank emissions with historical water production. In doing so, we found the strongest positive correlation between increased methane emissions from the tank and historical water production, showing the highest coefficient of determination value $\left(R^{2}=0.89\right)$ using 3 day total water production, see Figure S17. Therefore, we postulate that variability in tank emissions is primarily due to variability in water production, and total site emissions are impacted by a combination of both water and natural gas production. We aim to double our sample size within the next 24 months to better understand if current correlations continue to hold true.

\section{CONCLUSIONS AND RECOMMENDATIONS}

Numerous studies have focused on the quantification of methane emissions from natural gas sites. Many of these studies have focused on increasing sample sizes spatiotemporally to ensure representative results, however, our goal was to assess the temporal variability of emissions from an unconventional well site over the period of about 2 years (21 months). We completed direct quantification using a custom full flow sampling system with a measurement uncertainty of $\pm 10 \%$. Our results followed trends suggested by sampling multiple sites: most emissions were attributed to a smaller number of emitters, and like spatio-temporal measurements, temporal only measurements were also highly variable and driven by tank emissions. The total methane emissions from our site varied between 86.2 and $4102 \mathrm{~g} / \mathrm{h}$. If the average site emissions of $1371 \mathrm{~g} / \mathrm{h}$ were representative, using a single audit could have under estimated annual emissions by a factor of 16 or overestimated emissions by a factor of 3 . Thus, even with direct quantification methods, methane emissions remain highly variable, and a single snapshot in time may not accurately reflect average emissions rates. We note that even though measurements were repeated 6 times to assess variability, our data still may not encompass all variability, and we will continue to conduct audits over the next 18-24 months. The largest and most variable source of emissions from all audits was the produced water tank, whose peak emission was $3731 \mathrm{~g} / \mathrm{h}$. We examined our variable emissions compared to the total site production of natural gas and water production rates. Our strongest correlation was increased tank emissions as predicted from increased water production over a period of 3 days. A weaker correlation existed between total site emissions and 3 day water production rates. Overall, our component and site level emissions were typically within the range of minimum and maximum values reported in the literature. Thus, it is shown that repeated measurements at sites may yield significantly different results over time, depending on current and recent site activity.

\section{ASSOCIATED CONTENT}

\section{Supporting Information}

The Supporting Information is available free of charge on the ACS Publications website at DOI: 10.1021/acsomega.8b03246.

Site details (both physical and gas composition), additional details on FFS system and its use, audit conditions, exhaust stack emissions data, comparisons with other studies, and figures for the analysis of trends (PDF)

Audits 1-6, Measurement Results (XLSX)

\section{AUTHOR INFORMATION}

\section{Corresponding Author}

*E-mail: derek.johnson@mail.wvu.edu. Phone: 304-293-5725.

ORCID

Derek Johnson: 0000-0002-3189-5711

\section{Author Contributions}

The manuscript was written through equal contributions of all authors. All authors have given approval to the final version of the manuscript.

\section{Notes}

The authors declare no competing financial interest. 


\section{ACKNOWLEDGMENTS}

We thank industry collaborators for allowing us to collect these valuable data. This work was made possible under a grant from the Department of Energy's National Energy Technology Laboratory-DE-FE0024297. Observations and views expressed herein are those of the authors and do not necessarily represent the official views of the Department of Energy.

\section{ABBREVIATIONS}

$\mathrm{CH}_{4}$, methane; $\mathrm{CO}_{2}$, carbon dioxide; DJ, Denver-Julesburg; EPA, Environmental Protection Agency; EPGU, enclosed gas processing unit; FFS, full flow sampling system; $g / h$, grams per hour; GHG, greenhouse gas; GWP, global warming potential; IPCC, International Panel on Climate Change; MCF/day, thousand cubic feet per day; MMSCF, million standard cubic feet; ppm, parts per million; UGR, Upper Green River; US, United States

\section{REFERENCES}

(1) Alvarez, R. A.; Pacala, S.; Winebrake, J.; Chameides, W.; Hamburg, S. Greater focus needed on $\mathrm{CH} 4$ leakage from natural gas infrastructure. Proc. Natl. Acad. Sci. U.S.A. 2012, 109, 6435-6440.

(2) Wigley, T. M. L. Coal to gas: the influence of $\mathrm{CH} 4$ leakage. Clim. Change 2011, 108, 601-608.

(3) Myhre, G.; Shindell, D.; Bréon, F.-M.; Collins, W.; Fuglestvedt, J.; Huang, J.; Koch, D.; Lamarque, J.-F.; Lee, D.; Mendoza, B.; Nakajima, T.; Robock, A.; Stephens, G.; Takemura, T.; Zhang, H. In Anthropogenic and Natural Radiative Forcing, Climate Change 2013: The Physical Science Basis. Contribution of Working Group I to the Fifth Assessment Report of the Intergovernmental Panel on Climate Change; Cambridge University Press: Cambridge, United Kingdom, 2013.

(4) US Environmental Protection Agency. Inventory of U.S. Greenhouse Gas Emissions and Sinks, 1990-2015. https://www. epa.gov/sites/production/files/2016-04/documents/us-ghginventory-2016-main-text.pdf.

(5) Johnson, D. R.; Covington, A. N.; Clark, N. N. Design and Use of a Full Flow Sampling System (FFS) for the Quantification of Methane Emissions. J. Visualized Exp. 2016, 112, e54179.

(6) US Environmental Protection Agency. Overview of Greenhouse Gases. http://www3.epa.gov/climatechange/ghgemissions/gases/ ch4.html.

(7) Lyon, D. R. Quantifying, Assessing, and Mitigating Methane Emissions from Super-Emitters in the Oil and Gas Supply Chain. Theses and Dissertations; University of Arkansas, 2016. http:// scholarworks.uark.edu/etd/1492.

(8) Allen, D. T.; Torres, V. M.; Thomas, J.; Sullivan, D. W.; Harrison, M.; Hendler, A.; Herndon, S. C.; Kolb, C. E.; Fraser, M. P.; Hill, A. D.; Lamb, B. K.; Miskimins, J.; Sawyer, R. F.; Seinfeld, J. H. Measurements of methane emissions at natural gas production sites in the United States. Proc. Natl. Acad. Sci. U.S.A. 2013, 110, 1776817773.

(9) Allen, D.; Pacsi, A.; Sullivan, D.; Zavala-Araiza, D.; Harrison, M.; Keen, K.; Fraser, M.; Hill, A.; Sawyer, R.; Seinfeld, J. Methane emissions from process equipment at natural gas production sites in the united states: pneumatic controllers. Environ. Sci. Technol. 2015, 49, 633-640.

(10) Marchese, A.; Vaughn, T.; Zimmerle, D.; Martinez, D.; Williams, L.; Robinson, A.; Mitchell, A.; Subramanian, R.; Tkacik, D.; Roscioli, R.; Herndon, S. Methane emissions from United States gathering and processing. Environ. Sci. Technol. 2015, 49, 1071810727.

(11) Mitchell, A.; Tkacik, D.; Roscioli, J.; Herndon, S.; Yacovitch, T.; Martinez, D.; Vaughn, T.; Williams, L.; Sullivan, M.; Floerchinger, C.; Omara, M.; Subrmamanian, R.; Zimmerle, D.; Marchese, A.; Robinson, A. Measurements of methane emissions from natural gas gathering facilities and processing plants: measurement results. Environ. Sci. Technol. 2015, 49, 3219-3227.

(12) Subramanian, R.; Williams, L.; Vaughn, T.; Zimmerle, D.; Roscioli, J.; Herdon, S.; Yacovitch, T.; Floerchinger, C.; Tkacik, D.; Mitchell, A.; Sullivan, M.; Dallmann, T.; Robinson, A. Methane emissions from natural gas compressor stations in the transmission and storage sector: measurements and comparisons with the EPA greenhouse gas reporting program protocol. Environ. Sci. Technol. 2015, 49, 3252-3261.

(13) Johnson, D.; Covington, A.; Clark, N. Methane emissions from leak and loss audits of natural gas compressor stations and storage facilities. Environ. Sci. Technol. 2015, 49, 8132-8138.

(14) Zimmerle, D.; Williams, L.; Vaughn, T.; Quinn, C.; Subramanian, R.; Duggan, G.; Willson, B.; Opsomer, J.; Marchese, A.; Martinez, D.; Robinson, A. Methane emissions from the natural gas transmission and storage system. Environ. Sci. Technol. 2015, 49, 9374-9383.

(15) Lamb, B.; Edburg, S.; Ferrara, T.; Howard, T.; Harrison, M.; Kolb, C.; Townsend-Small, A.; Dyck, W.; Possolo, A.; Whetstone, J. Direct measurements show decreasing methane emissions from natural gas local distribution systems in the United States. Environ. Sci. Technol. 2015, 49, 5161-5169.

(16) Clark, N.; McKain, D.; Johnson, D.; Wayne, S.; Li, H.; Akkerman, V.; Sandoval, C.; Covington, A.; Mongold, R.; Hailer, T.; Ugarte, O. Pump-to-wheels methane emissions from the heavy-duty transportation sector. Environ. Sci. Technol. 2017, 51, 968-976.

(17) US Energy Information Agency. Hydraulically Fractured Wells Provide Two-Thirds of U.S. Natural Gas Production, 2016. https:// www.eia.gov/todayinenergy/detail.php?id=26112.

(18) Omara, M.; Sullivan, M. R.; Li, X.; Subramanian, R.; Robinson, A. L.; Presto, A. A. Methane emissions from conventional and unconventional natural gas production sites in the Marcellus shale basin. Environ. Sci. Technol. 2016, 50, 2099-2107.

(19) Vaughn, T.; Bell, C.; Pickering, C.; Schwietzke, S.; Heath, G.; Petron, G.; Zimmerle, D.; Schnell, R.; Nummedal, D. 2018. Temporal variability largely explains top-down/bottom-up difference in methane emissions estimates from a natural gas production region. Proc. Natl. Acad. Sci. U.S.A. 2018, 115, 11712-11717.

(20) Howard, H. M. High Flow Rate Sampler for Measuring Emissions at Process Components. U.S. Patent US5563335A, 1996.

(21) Howard, T.; Ferrara, T. W.; Townsend-Small, A. Sensor transition failure in the high flow sampler: Implications for methane emissions inventories of natural gas infrastructure. J. Air Waste Manage. Assoc. 2015, 67, 852-862.

(22) Howard, T. University of Texas study underestimates national methane emissions at natural gas production sites due to instrument sensor failure. Energy Sci. Eng. 2015, 3, 443-455.

(23) Johnson, D.; Heltzel, R. Methane emissions measurements of natural gas components using a utility terrain vehicle and portable methane quantification system. Atmos. Environ. 2016, 144, 1-7.

(24) Los Gatos Research. Ultraportable Greenhouse Gas Analyzer, 2017. http://www.lgrinc.com/analyzers/ultraportable-greenhousegas-analyzer/.

(25) Rella, C. W.; Tsai, T. R.; Botkin, C. G.; Crosson, E. R.; Steele, D. Measuring emissions from oil and natural gas well pads using the mobile flux plane technique. Environ. Sci. Technol. 2015, 49, 47424748.

(26) Bell, C.; Vaughn, T.; Zimmerle, D.; Herndon, S.; Yacovitch, T.; Heath, G.; Petron, G.; Edie, R.; Field, R.; Murphy, S.; Robertson, A.; Soltis, J. Comparison of methane emissions estimates from multiple measurement techniques at natural gas production pads. Elem. Sci. Anth. 2017, 5, 79.

(27) Yacovitch, T. I.; Herndon, S. C.; Pétron, G.; Kofler, J.; Lyon, D.; Zahniser, M. S.; Kolb, C. E. Mobile laboratory observations of methane emissions in the Barnett shale region. Environ. Sci. Technol. 2015, 49, 7889-7895.

(28) Robertson, A. M.; Edie, R.; Snare, D.; Soltis, J.; Field, R. A.; Burkhart, M. D.; Bell, C. S.; Zimmerle, D.; Murphy, S. M. Variation in methane emission rates from well pads in four oil and gas basins with 
contrasting production volumes and compositions. Environ. Sci. Technol. 2017, 51, 8832-8840.

(29) Goetz, J. D.; Floerchinger, C.; Fortner, E. C.; Wormhoudt, J.; Massoli, P.; Knighton, W. B.; Herndon, S. C.; Kolb, C. E.; Knipping, E.; Shaw, S. L.; DeCarlo, P. F. Atmospheric emission characterization of Marcellus shale natural gas development sites. Environ. Sci. Technol. 2015, 49, 7012-7020.

(30) Yacovitch, T.; Daube, C.; Vaugh, T.; Bell, C. S.; Roscioli, J.; Knighton, W. B.; Nelson, D.; Zimmerle, D.; Pétron, G.; Herndon, S. C. Natural gas facility methane emissions: measurements by tracer flux ratio in two US natural gas producing basins. Elem. Sci. Anth. 2017, 5, 69 .

(31) Alvarez, R.; Lyon, D.; Marchese, A.; Robinson, A.; Hamburg, S. Possible malfunction in widely used methane sampler deserves attention but poses limited implications for supply chain emissions estimates. Elem. Sci. Anth. 2016, 4, No. 000137.

(32) Iglewicz, B.; Hoaglin, D. In How to Detect and Handle Outliers; Mykytka, E. F., Ed.; ASQC Quality Press: California, 1993; Vol. 16.

(33) Kang, M.; Kanno, C. M.; Reid, M. C.; Zhang, X.; Mauzerall, D. L.; Celia, M. A.; Chen, Y.; Onstott, T. C. Direct measurements of $\mathrm{CH} 4$ emissions from abandoned oil and gas wells in Pennsylvania. Proc. Natl. Acad. Sci. U.S.A. 2014, 111, 18173-18177.

(34) Townsend-Small, A.; Ferrara, T. W.; Lyon, D. R.; Fries, A. E.; Lamb, B. K. Emissions of coalbed and natural gas methane from abandoned oil and gas wells in the United States. Geophys. Res. Lett. 2016, 43, 2283-2290. 